\section{AS ÂNFORAS PANATENAICAS DO MUSEU ARQUEOLÓGICO NACIONAL DE ATENAS}

\author{
Camilla Miranda Martins* \\ Recebido em 06/08/2020 \\ Aceito em 09/10/2020
}

\begin{abstract}
RESUMO: O objetivo principal deste artigo é refletir sobre a relação entre presente e passado a partir do estudo das ânforas panatenaicas e de outras cerâmicas do universo panatenaico, expostas no Museu Arqueológico Nacional de Atenas. Estudam-se quinze objetos datados entre 575 e 359 a.C., provenientes dos jogos do Festival das Panateneias, evento cívico e religioso que ocorria em Atenas em homenagem à deusa políade e em cujas competições atléticas os vencedores ganhavam ânforas contendo o azeite sagrado das oliveiras de Atena. Com essa cultura material e a partir da análise da concepção de sua exposição, pretendese indagar a respeito da contemporaneidade em relação a questões de identidade nacional, as quais permitem problematizar o esporte como elemento de construção da nação, a Grécia.
\end{abstract}

PALAVRAS-CHAVE: vasos gregos; festival das Panateneias; Museu Arqueológico Nacional de Atenas; identidade nacional.

\section{THE PANATHENAIC AMPHORAE OF NATIONAL ARCHAEOLOGICAL MUSEUM OF ATHENS}

\begin{abstract}
This paper aims to discuss the relationship between present and past, considering the study of Panathenaic amphorae and other Panathenaic pottery exhibited at the National Archaeological Museum of Athens. Fifteen objects dated from 575 to 359 BC are studied, they were from the games of the Panathenaic Festival, a civic and religious event that took place in Athens in honor of the polyad goddess, and in which athletic competitors won amphorae containing the sacred olive oil from the olive trees of Athena. With this material culture, and from the analysis of the conception of its exhibition, it is intended to inquire about contemporaneity in relation to issues of national identity, which allow problematizing sport as an element of nation building, in Greece case.
\end{abstract}

KEYWORDS: Greek vases; Panathenaic festival; National Archaeological Museum of Athens; national identity.
*Doutora em História, Universidade Federal do Paraná.

camillamirandamartins@ yahoo.com.br

(iD) 


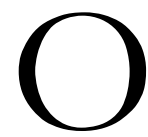

lhar o passado é entender, de certa forma, o presente. Essa é a discussão principal deste artigo, fruto de minha tese, e que, por meio do estudo das ânforas panatenaicas expostas no Museu Arqueológico Nacional de Atenas (NAM), busca uma compreensão sobre como objetos reunidos numa exposição, de acordo com certa perspectiva, dão sentido ao presente. No caso, se analisa como a temática dos agônes na Antiguidade é ressignificada permitindo certa continuidade entre o atleta antigo e o contemporâneo, em uma perspectiva de construção da nação, a Grécia.

O festival panatenaico era uma festa que ocorria em Atenas, composta por competições, procissão, sacrifício e banquete, tudo em homenagem à deusa políade. A cada quatro anos havia as Grandes Panateneias, que recebiam estrangeiros e nas quais as ânforas panatenaicas eram oferecidas com azeite sagrado como prêmio aos competidores.

Essas ânforas constituem-se, de maneira geral, por exceções de produção ceramista com figuras negras que não deixaram de ser feitas mesmo depois de a técnica com figuras vermelhas estar no auge. Sua iconografia se distribui em dois painéis, um com uma cena dos jogos e outro com a imagem de Atena Prômacos entre duas colunas, podendo ou não ter a inscrição dos prêmios de Atenas. É importante ressaltar que a caracterização desse objeto é problemática (cf. Francisco, 2012), mas a sua materialidade é um documento rico em informações, apesar de não acompanhar o festival durante todo o período no qual foi celebrado.

Enfim, a intenção de estudar o lugar onde está o objeto, parte do argumento de que o historiador faz escolhas mediadas pelo seu próprio meio. Em outras palavras, surge do questionamento de como se constrói a documentação, mais especificamente a cultura material e as ânforas panatenaicas, e em como isso é influenciado pelo museu, instituição responsável pela guarda, pesquisa e difusão dos objetos.

\section{O PASSADO DA GRÉCIA}

Há, conforme Tziovas (2008, p. 287-8), quatro modelos para o entendimento do passado grego: 1) o simbólico ou arqueológico, no qual o renascimento do passado clássico supera a distância entre o passado e o presente em um nível simbólico, principalmente pela purificação de monumentos e de quaisquer outros vestígios antigos; 2) o esquema orgânico ou romântico, que vê o passado como algo vivo no presente e no qual a nostalgia de um grande passado é substituída pela de autenticidade; 3) o modelo estético ou modernista, com uma visão dinâmica da identidade grega e com uma presença do passado no presente mais estética do que histórica; 4) o modelo crítico ou pós-modernista, que entende o passado como aberto a contínuas interpretações e rearranjos; nele, a noção de continuidade histórica é deixada de lado e é dada preferência ao estudo de rupturas, silêncios e períodos negligenciados. Essas não são as únicas perspectivas para se perceber o passado, mas são instrutivas para se entender as forças que moldam as exibições dos museus (Gazi, 2011, p. 365).

Neste artigo, o debate em torno do passado da Grécia centra-se na concepção de identidade nacional, a qual, nos Estudos Clássicos, de acordo com Silva (2005, p. 97), sempre existiu, desde o pleitear de uma herança justificadora ampla (a civilização, transmitida dos 
antigos para os modernos), até a legitimação de regimes autocráticos de direito. Segundo Díaz-Andreu (2007, p. 33), isso aconteceu porque a Antiguidade Clássica e a cultura material foram usadas como metáforas para uma nova forma de poder político.

De maneira geral, neste texto, a análise específica busca compreender se existe alguma ideia de identidade nacional difundida na exposição do NAM, particularmente das ânforas panatenaicas, além disso, nesse caso, os modelos de Tziovas também serão aplicados.

Apesar de existir diversidade no entendimento do nacionalismo, aqui ele é compreendido como a estrutura orientadora do significado da nação e como um processo de construção imaginária da sociedade que começou com os europeus dos séculos XVIII e XIX, que buscavam uma ascendência antiga, étnica e gloriosa que lhes garantisse reivindicar um parentesco racial com os gregos e romanos, a fim de fundar seus direitos de possessão, imperialistas e colonialistas. Isso, como explica Silva (2005, p. 93), ocasiona a ideia de continuidade em relação ao passado histórico, tanto étnica como de algumas instituições, evocando certa ancestralidade e antiguidade da nação, e perpetuando identidades nas imagens da vida nacional. Assim, a concepção moderna de nação constituiu-se em uma categoria identitária política e ideologicamente orientada, construída e não dada naturalmente.

Na Grécia, pelo menos até o final do século XVIII, a lacuna entre o mundo antigo e o mundo moderno era parcialmente promovida pela Igreja, que lembrava às pessoas que elas eram, em primeiro lugar, cristãs ortodoxas, e que a denominação "helena" ainda era identificada como pagã. Contudo, isso começou a mudar quando um sentido de tempo contínuo passou a se desenvolver, ganhando forma o que se denomina de modelo simbólico ou arqueológico de interpretação do passado, e quando entrou em moda uma ideia de que as musas estariam retornando à Grécia após um exílio temporário na Europa Ocidental, durante o período otomano (Tziovas, 2008, p. 288).

Essa perspectiva também começou a se modificar a partir do entendimento do europeu ocidental do fim do século XVIII e início do XIX (denominado de fileleno), para quem os gregos modernos eram os descendentes diretos da Grécia antiga, origem da civilização e berço das nações ocidentais, da política e da liberdade. Nessa ideia, era inaceitável a Grécia ser cristã e estar sob o domínio islâmico do Império Otomano e, por isso, para uma regeneração helênica, a independência seria a melhor opção (Díaz-Andreu, 2007, p. 82).

Essa independência de fato ocorreu após muitos anos de guerra (1821-1832) e a Grécia viu nas antiguidades uma metáfora não só para a civilização, mas também para a delimitação e formação do seu próprio território, bem como para os seus próprios direitos políticos. O antigo passado grego se tornou, assim, a evidência do direito do país à autodeterminação (Díaz-Andreu, 2007, p. 80).

Nesse contexto, Atenas foi considerada o lugar de origem da democracia, reintegrada como a capital da Grécia em 1833 e a Grécia moderna foi inventada por uma convergência dos processos colonial e nacional. Hamilakis (2007) denomina helenismo indígena a narrativa autônoma que surgiu da necessidade de abordar a descontinuidade temporal na narrativa nacional, como a "escravização" e a "morte” da nação em 338 a.C. na batalha de Queroneia, até a sua ressurreição em 1821 nas lutas pela independência. Essa tensão foi resolvida pelos folcloristas por meio de uma síntese religiosa, coletando vestígios das antigas religiões gregas 
na tradição ortodoxa e colocando ênfase em seus aspectos materiais, por exemplo, com o estabelecimento de igrejas em locais de adoração antiga. O helenismo indígena propôs, dessa forma, uma continuidade espiritual e cultural, que reabilitou Bizâncio, formalizou os laços com a teologia cristã e construiu um mundo clássico mais à vontade no oriente cristão ortodoxo do que no ocidente católico e protestante (Hamilakis, 2007, p. 123).

Assim, a partir do exemplo da Grécia, entende-se que o passado é constituído por traços, cuja construção e reconstrução são sempre parciais, formando certa imagem da história. Nesse entendimento, o passado não é um campo neutro de discurso e, como explica Meskell (2002, p. 3), é necessário estar ciente de que as cartografias e os mapeamentos modernos são inscrições recentes, não tendo paralelos contíguos na Antiguidade. Isso, neste artigo, gera um questionamento a respeito de como determinado documento (no caso as ânforas panatenaicas) e certo passado (o Festival das Panateneias e os jogos) são moldados e apresentados.

\section{O MUSEU}

Desde a Revolução Francesa, o conceito de cidadania passa pela possessão do patrimônio público. "Ser cidadão e pertencer a uma nação implica imbuir-se de um passado tangível, materializado no patrimônio.” (Ferreira, 2008, p. 40). Criam-se, por meio dele, as tradições nacionais, que incutem nas memórias o que deve ser excluído e incluído, o que deve ser lembrado e cultuado, esquecido e silenciado. Nesse sentido, nenhum governo governa sem patrimônio. Essa é uma concepção que adquire forma no colonialismo e conecta-se diretamente ao nacionalismo.

De acordo com Díaz-Andreu (2007, p. 42), antes dos museus, as coleções eram vistas como forma de continuar e preservar a imagem de uma pessoa, a do erudito e do seu patrocinador, mas, com a criação dessas instituições públicas, passaram a ser entendidas como um reforço da imagem da nação. Assim, segundo Francisco (2015, p. 196), a organização dessas coleções em instituições públicas relaciona-se ao nacionalismo, à criação de identidade nacional e à administração do Estado. Nesse cenário, "O vaso não é apenas grego, mas passa a assumir um valor específico como propriedade de instituições e como patrimônio nacional" (Francisco, 2015, p. 201).

Aqui os museus são entendidos a partir da relação com certa identidade nacional pleiteada, formulada e representativa de um passado. No caso da Grécia, aqueles nacionais por excelência são três: o NAM, o Museu Bizantino e Cristão e o Museu Grego de Cultura Folclórica. Resumidamente, são assim considerados por quatro motivos: 1) referem-se aos três períodos canônicos da história grega (antigos, bizantinos e modernos); 2) exibem importantes obras e informam ao público o que é patrimônio nacional; 3) elaboram e difundem a noção de continuidade histórica da nação e sua unidade no tempo e no espaço; 4) são "considerados como loci de 'segurança imaginária', longe de noções perturbadoras de alteridade, descontinuidade e inquietação contemporânea” (Gazi, 2011, p. 373).

Pode-se afirmar, ainda, que nesses museus o destaque político são as antiguidades e a herança clássica, porque detêm valor simbólico, conectados com a estética e o pensamento 
filosófico e político da Grécia Clássica, considerados parte do grande passado Europeu e a base da civilização ocidental - de acordo com o modelo estético ou modernista de interpretação do passado.

Há, certamente, mudanças ocorrendo nessa gestão. A participação organizada de baixo para cima de vários agentes na proteção e defesa de antiguidades, por exemplo, está ganhando terreno e apoio legislativo. Também existe a tendência de reconciliação com o patrimônio contestado (modelo crítico ou pós-modernista de interpretação do passado), refletindo uma maturidade científica e política alinhada com as políticas de tolerância e diversidade da União Europeia (Kouri, 2017, p. 55).

Entretanto, a referência ou a representação de outros grupos étnicos, religiosos ou de minorias ainda é pouco e superficialmente abordada. Isso é evidente, por exemplo, nas exibições do NAM que descrevem a história grega como habitada quase exclusivamente por homens corajosos; especialmente os homens que a história oficial endossou como heróis nacionais (Gazi, 2011, p. 391-2). Assim, em um museu nacional como esse, uma exposição irá ensinar a cultura do antigo mundo grego, transferir a beleza da antiga arte grega para os visitantes e/ou transmitir a ideia de um passado ideal.

Embora raramente haja um itinerário predeterminado para os visitantes, o arranjo cronológico das descobertas sugere uma direção, a rota da continuidade nacional e da história. O caminho das pessoas dentro do museu é, quase sempre, de uma caixa de vidro (box) para a outra e de um período para o outro, pois, dessa forma, reencena-se a história nacional e colocam-se os artefatos, sinalizados com datas e lugares de origem, como os marcos do território percorrido na exposição (Hamilakis, 2007, p. 48).

$\mathrm{Na}$ verdade, é compreensível que abordagens recentes estejam progredindo lentamente, pois a administração de antiguidades tem sido centrada no governo desde o surgimento do Estado Grego Moderno e, ainda, há uma longa tradição de proteção física dos bens culturais que envolve salvaguardar os seus valores simbólicos e estéticos (Grillo, 2017a).

Enfim, é importante lembrar que os museus na contemporaneidade, em especial na Grécia, possuem objetivos diversos. Nem sempre mostram valores e mitos nacionais, às vezes promovem a análise e o debate da cultura local, da região onde estão, como, por exemplo, o Museu Arqueológico de Tessalônica. Outras vezes articulam com o presente um passado por vezes silenciado na perspectiva dos mitos nacionais, como o Museu de Arte Islâmica Benaki.

Nesse contexto, a escolha pelo NAM ocorreu porque é o principal museu arqueológico nacional da Grécia, apesar de no país existirem outras instituições, como o Museu de Náuplia e muitos outros. Optou-se, fundamentalmente, por refletir sobre a cidade de Atenas, local do festival das Panateneias na Antiguidade e, na contemporaneidade, centro das atenções dentro das discussões sobre o nacionalismo grego.

A capital, por sua vez, também possui diversos museus interessantes para estudo como o Museu da Acrópole. Entretanto, buscou-se um museu com a exposição de ânforas e outras cerâmicas do universo panatenaico e que ainda fosse motivo de debates sobre a identidade da nação. O Museu da Acrópole também possui ânforas panatenaicas e representa a identidade nacional, principalmente para os visitantes e turistas, pois é um museu central 
e ao lado de uma das entradas para a Acrópole, por isso, ele é bem frequentado. Contudo, sua preocupação principal está na escultura e na arquitetura monumental do Partenon. Nele a exposição da cerâmica, em especial das ânforas panatenaicas, não é central.

Já o NAM, apesar de não estar no centro de Atenas, é um museu que abrange tanto a escultura como a cerâmica e outros objetos, como elementos essenciais da Antiguidade na Grécia. Por ser considerado o museu nacional mais tradicional do país, também está no circuito dos museus mais visitados.

O NAM, segundo Gazi (2011, p. 378-379), é “O” museu nacional da Grécia, pois representa um dos mitos nacionais mais profundamente enraizados e dominantes, a origem da Grécia moderna na antiga Hélade. A narrativa principal do NAM, iniciada no último quartel do século XIX e aperfeiçoada nos anos 1910, é colocar as antiguidades em exibição como "verdades objetivas". Isso, apesar de algumas mudanças e de coleções menores que não entram nessa dinâmica, manteve-se, bem como o caráter de ícone nacional da instituição.

Foi fundado em 1829, após a independência da Grécia e a criação do Estado grego. Também foi o primeiro museu estabelecido no país e originalmente estava na ilha de Egina, antiga capital da região. Oficialmente, foi inaugurado por decreto presidencial de 9 de agosto de 1893 com o objetivo de promover "o estudo e o ensino da ciência da arqueologia, a propagação do conhecimento arqueológico e o cultivo de um amor pelas Belas Artes” (National Archaeological Museum, 2018c).

A relevância do museu na Grécia, de acordo com a sua diretora, LagogianiGeorgakarakos (2016, p. 1-2), reside em seu objetivo de construir uma imagem multinacional do passado arqueológico da cultura grega, o que indica a importância da instituição no entendimento do passado grego e na própria identidade nacional.

\section{Os VASOS GREgos}

Conforme Phillippak (1970, p. 7), os vasos gregos possuem um lugar importante em muitos museus, pois refletem a grandeza do seu tempo mesmo no menor dos produtos. São antiguidades e também possuem valor de arte. São sempre trabalhos originais, o que, às vezes, não é o caso das esculturas. São interessantes tanto pela sua pintura como pela sua forma, e a decoração junto com a composição são notáveis, uma vez que se adaptam à materialidade do vaso. Além disso, há referências ao trabalho dos pintores na literatura indicando que era algo bem-visto na Antiguidade e os temas são fonte exaustiva de conhecimento de todos os aspectos da vida no mundo antigo.

Segundo Kaltsas (2010, p. 68-9):

Eles nos dão uma visão valiosa sobre a pintura monumental de seu tempo, uma vez que, ainda, poucos exemplos de outras obras, como pintura de parede e imagens independentes, foram encontrados. Por meio das cenas retratadas neles, nos familiarizamos com todos os aspectos da vida antiga, tanto público como privado: mitologia, religião, costumes, competições atléticas e intelectuais, e o teatro, para citar apenas alguns. Seja o trabalho de artistas anônimos ou assinados 
por renomados pintores de vasos, eles nos dão uma imagem realista de seus tempos que os tornam acessíveis não apenas ao especialista, mas também ao visitante comum.

Assim, por todas as suas qualidades, a coleção de vasos do NAM ocupa um lugar particularmente importante entre as exibições. De acordo com Phillippak (1970, p. 6), é uma das coleções de vasos mais rica no mundo, sendo particularmente importante por causa dos vasos geométricos do século VII a.C. e dos lécitos de fundo branco. Para essa autora, também é digna de nota a última sala dedicada ao século IV, onde o visitante pode ver produtos das oficinas áticas lado a lado.

De fato, o estudo dos vasos permite um conhecimento de todos os aspectos da vida na Antiguidade e no museu isso pode ser acessível tanto para o especialista como para o visitante. Contudo, é importante considerar que são objetos construídos pelo pesquisador e pela própria instituição, portanto, o passado a que se referem pode ser interpretado de diferentes maneiras.

Então, afirmar que, como Kaltsas, a iconografia dos vasos gregos transmite uma imagem realista da Antiguidade é problemático, pois “deve-se notar que a proposta relação entre esse repertório figurativo ático e estruturas muito mais amplas correspondentes ao mundo grego está, em muitos casos, conectada a uma noção unificada sobre a Grécia na Antiguidade; o que é amplamente debatido." (Francisco, 2016, p. 11).

No caso das ânforas panatenaicas, o evento que demandava sua produção, conforme Francisco (2016), usualmente é visto como um referencial para a própria figuração atlética na Antiguidade grega de forma geral, porém, as Panateneias tinham suas particularidades em relação a outros festivais e concursos. "Essa compreensão que toma a parte pelo todo, aproxima-se fortemente da formulação da Grécia Antiga como uma unidade, quase um estado nacional, no qual as distinções locais são, em grande medida, atenuadas" (Francisco, 2016, p. 11).

\section{A EXPOSIÇÃo}

Em junho e julho de 2018 a exposição de vasos gregos do NAM segue uma linha cronológica e narra a história da pintura vascular que começa, aproximadamente, no século XI a.C., mostrando as influências do passado micênico na produção geométrica (cerca de 1050 a 700 a.C.), indo gradualmente da cerâmica geométrica para aquela com cenas narrativas, apresentando peças do período orientalizante (cerca de 700 a 600 a.C. - dispondo de objetos protocoríntios e proto-áticos), da época Arcaica (aproximadamente 600 a 500 a.C.) e Clássica (entre 500 e 300 a.C.), evidenciando a técnica de figuras negras e, depois, a de figuras vermelhas.

Além disso, o caminho da exposição está sinalizando as regiões de onde vieram as cerâmicas e, sempre que possível, os pintores responsáveis pelas figurações. Mostra, ainda, as características do estilo de figuras negras arcaico "maduro" (de 570 a cerca de 530 a.C.), as placas funerárias de figuras negras e as diferentes formas dos vasos áticos entre os séculos VI e IV a.C. 
Nesse trajeto, o objeto 1 (fig. 1) é mostrado como um exemplar de ânfora ática de figuras negras e ao seu lado lê-se o que eram, quais seus tipos ou formas, como eram constituídas, como eram suas figurações e para que serviam. Nesse painel explicativo lê-se que a ânfora panatenaica é uma categoria especial de ânforas de figuras negras com pescoço que continham o óleo das oliveiras sagradas de Atenas e eram distribuídas como prêmios pelo estado ateniense a cada quatro anos no festival da Grande Panateneia. Assim, a discussão em torno da caracterização desse objeto não aparece.

$\mathrm{Na}$ verdade, em nenhum momento as informações sobre as cerâmicas são problematizadas. Dessa maneira, a linha expositiva apresenta uma história coesa e evolutiva sobre o passado ao qual essa cultura material se refere e, nesse sentido, o visitante pode pensar que suas figurações transmitem uma imagem realista da Antiguidade.

Nessa linha teleológica, o antecedente da ânfora panatenaica seria a ânfora protopanatenaica (objeto 1).

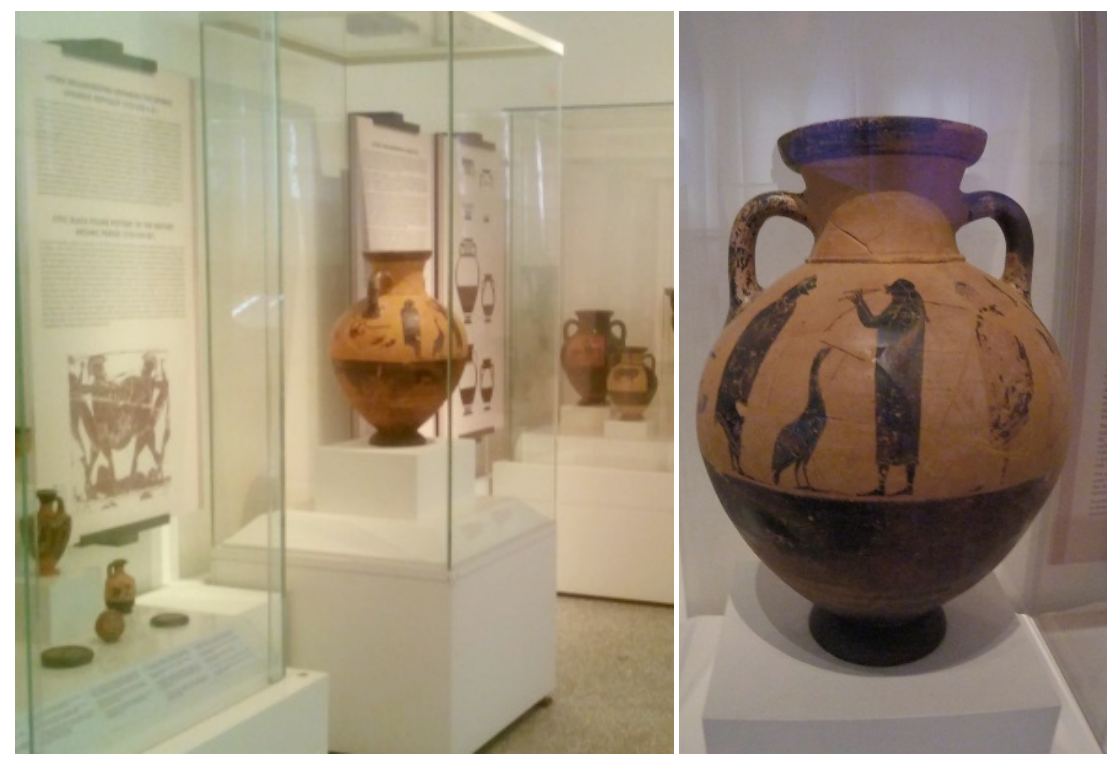

Figura 1 - Objeto 1. Ânfora proto-panatenaica.

Fonte: Museu Arqueológico Nacional de Atenas, foto de Camilla Martins.

(C) Hellenic Ministry of Culture and Sports / Archaeological Receipts Fund.

Depois de se observar os diversos tipos de ânforas e certo desenvolvimento da cerâmica, apresentam-se as ânforas panatenaicas de 2 a 7 . Todas se encontram em destaque (fig. 2) e, no texto do seu painel, primeiro explica-se o que eram as Panateneias e o contexto dos jogos dentro do festival. Então, esclarece-se o que eram as ânforas, recipientes especiais que carregavam o prêmio dos ganhadores das competições, o azeite sagrado. Por fim, no último parágrafo definem-se as suas figurações, dando a entender que elas sempre possuem tanto a inscrição dos jogos como a do arconte do ano (o que é questionável). 

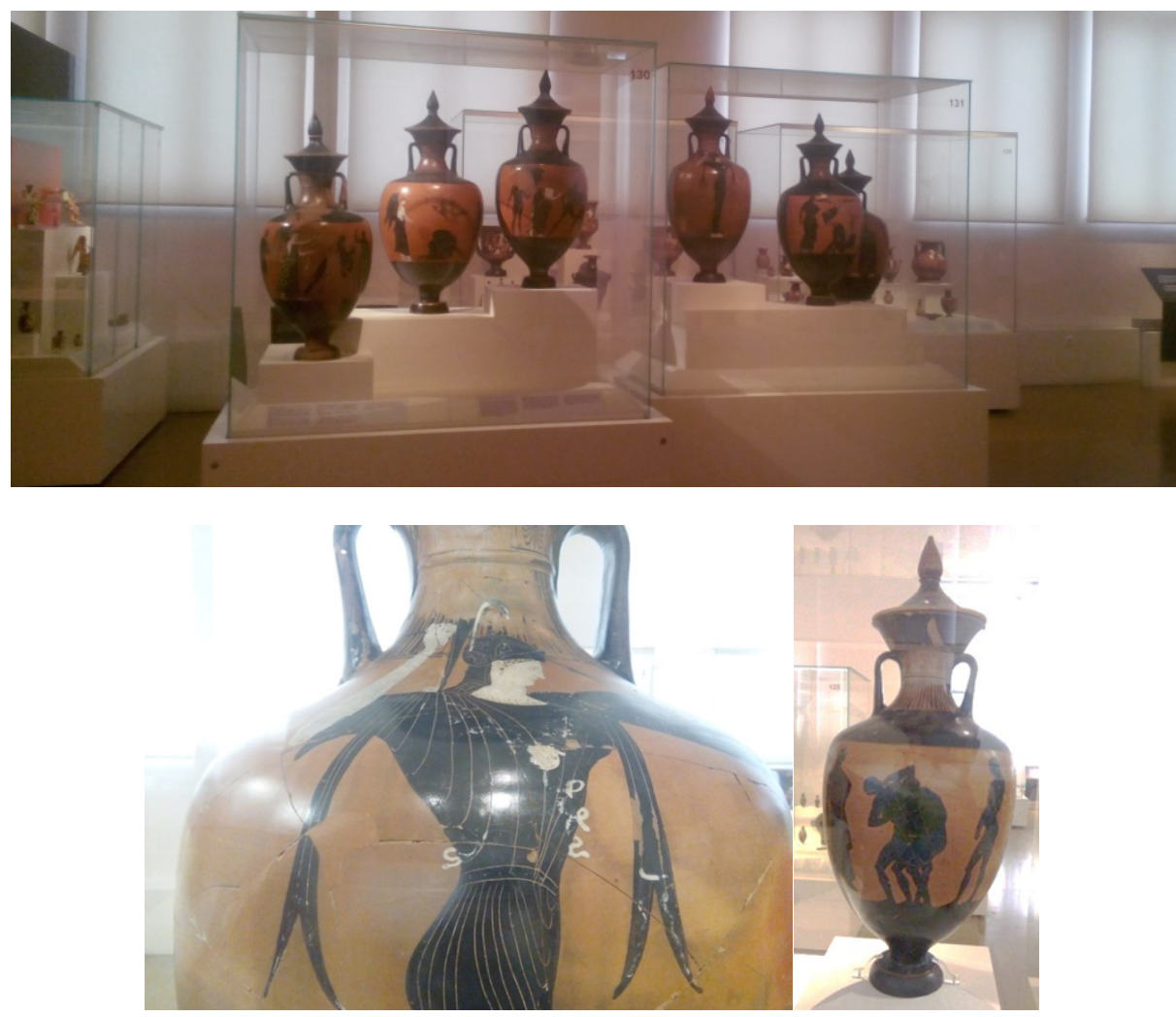

Objeto 2

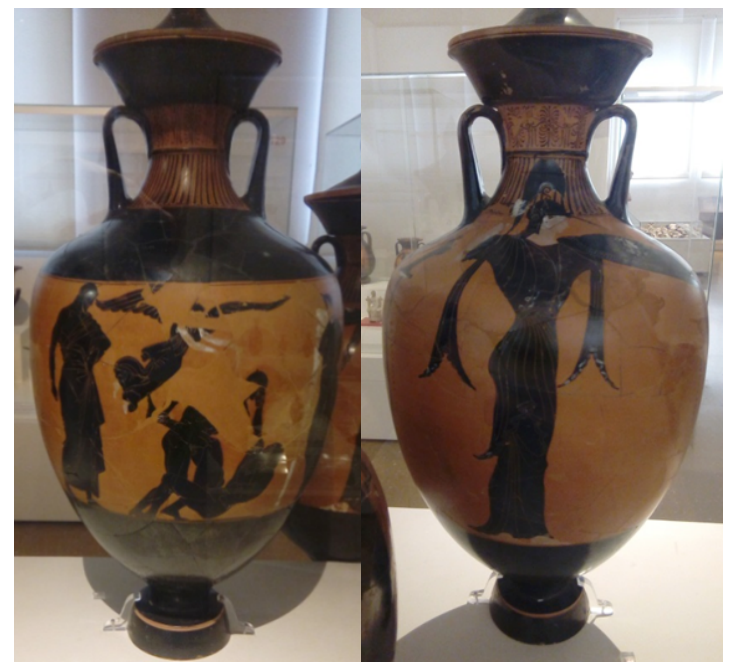

Objeto 3 


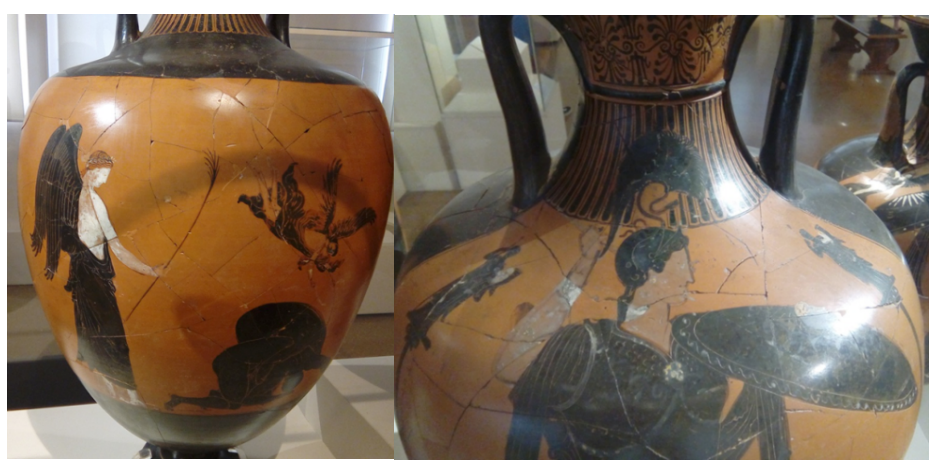

Objeto 4

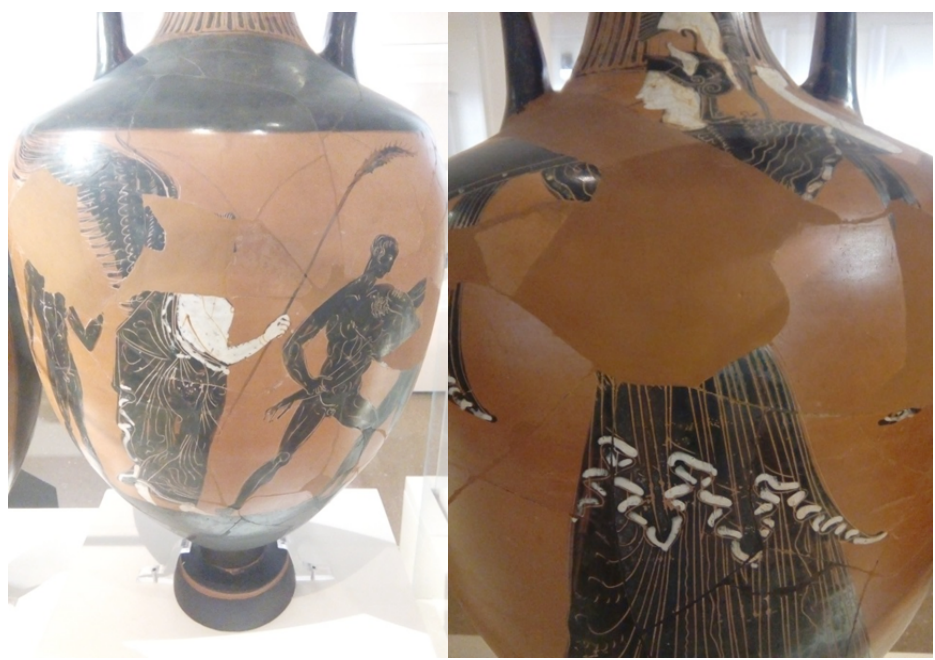

Objeto 5

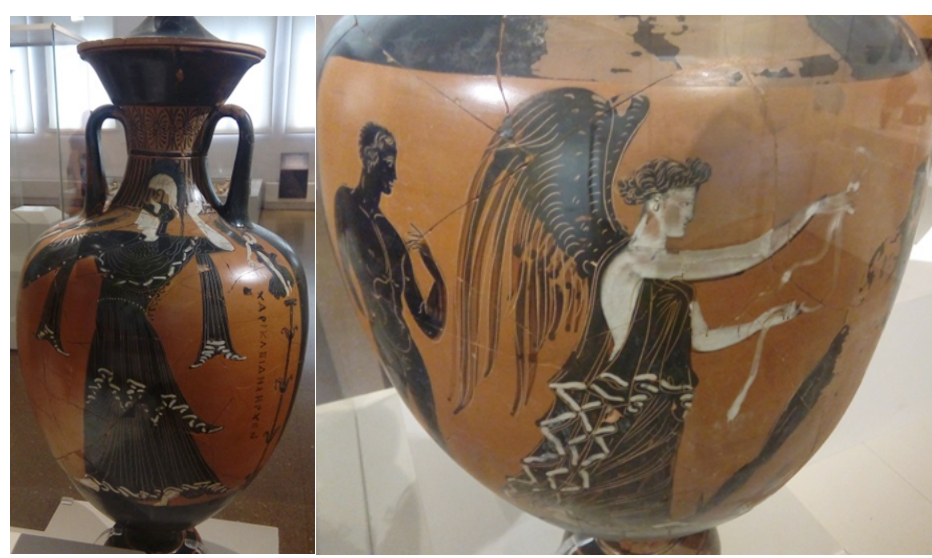

Objeto 6 


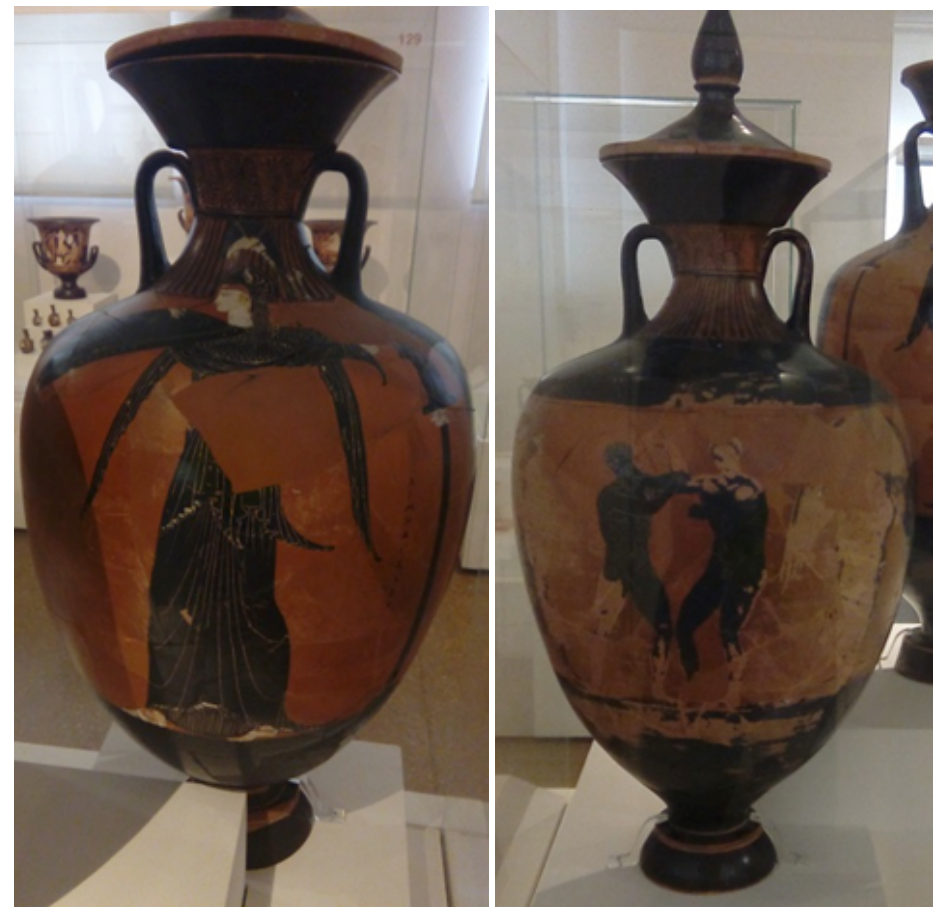

Objeto 7

Figura 2 - Objetos 2 a 7. Ânforas panatenaicas.

Fonte: Museu Arqueológico Nacional de Atenas, foto de Camilla Martins.

(C) Hellenic Ministry of Culture and Sports / Archaeological Receipts Fund.

Por fim, a última sala da exposição é uma sala temática, dedicada a cenas de competição, de esportes e de vitória (fig. 3 e 4). Nela estão os demais objetos de análise, sendo que a ânfora 15 possui destaque especial, pois é a última peça do trajeto expositivo e é a única do seu box (fig. 4).

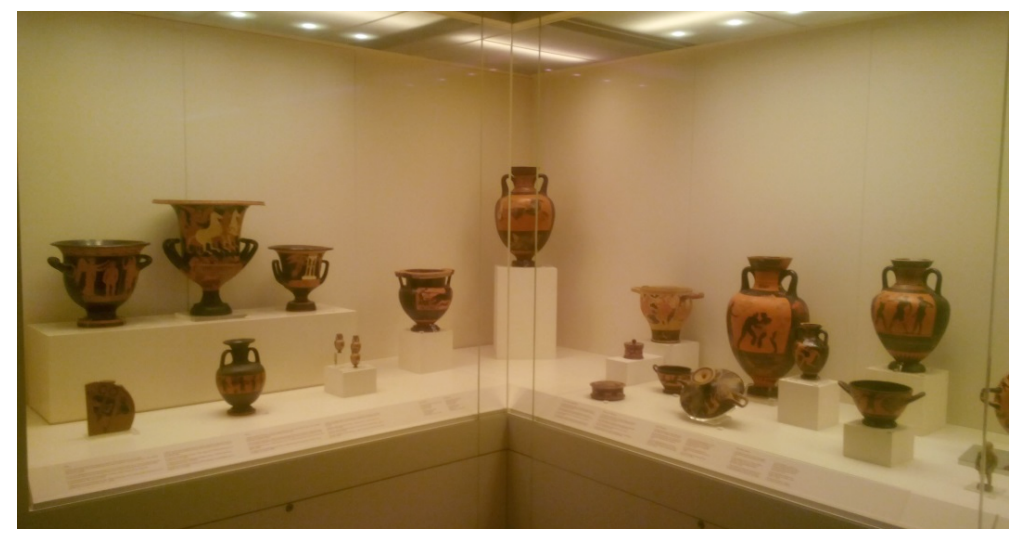




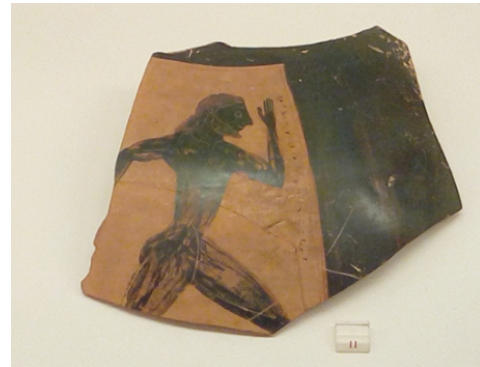

Objeto 8

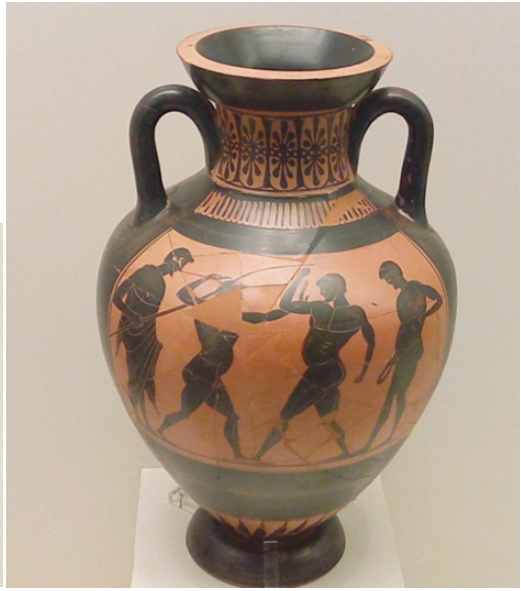

Objeto 9

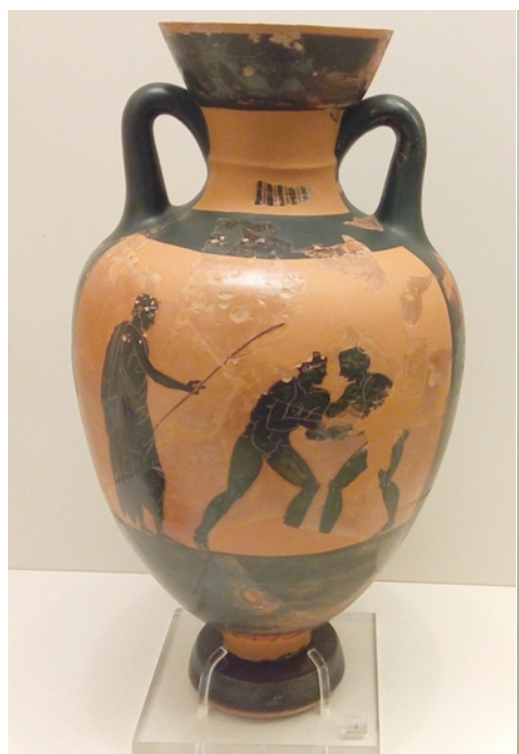

Objeto 10

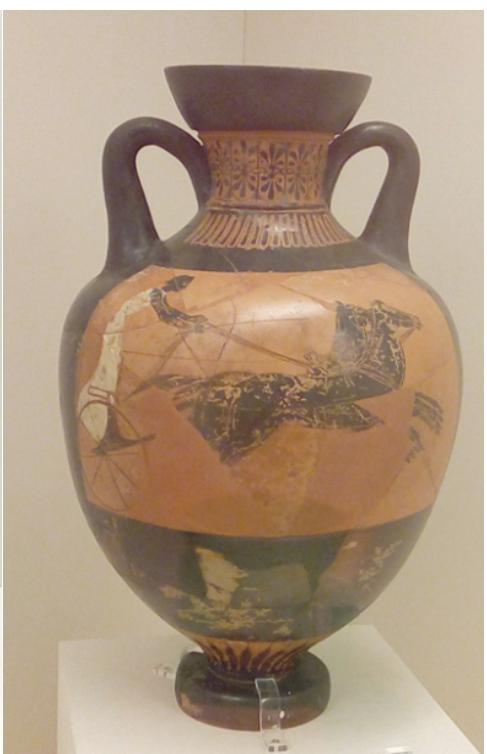

Objeto 11 


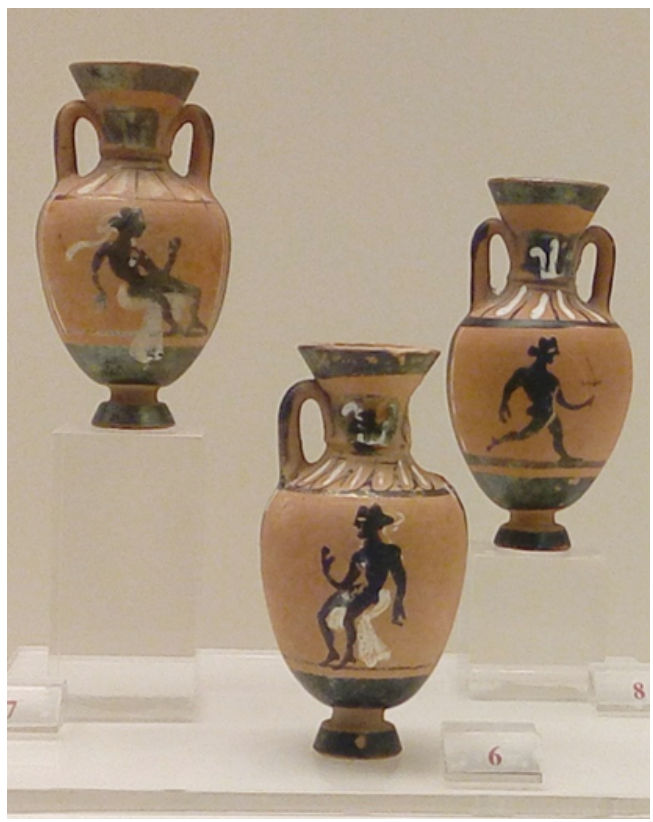

Objeto 12 (centro); objeto 13 (lado esquerdo); objeto 14 (lado direito)

Figura 3 - Objetos 8 a 14. Duas ânforas panatenaicas, um fragmento de ânfora panatenaica, três miniaturas e uma ânfora de figuras negras.

Fonte: Museu Arqueológico Nacional de Atenas, foto de Camilla Martins. (C) Hellenic Ministry of Culture and Sports / Archaeological Receipts Fund.

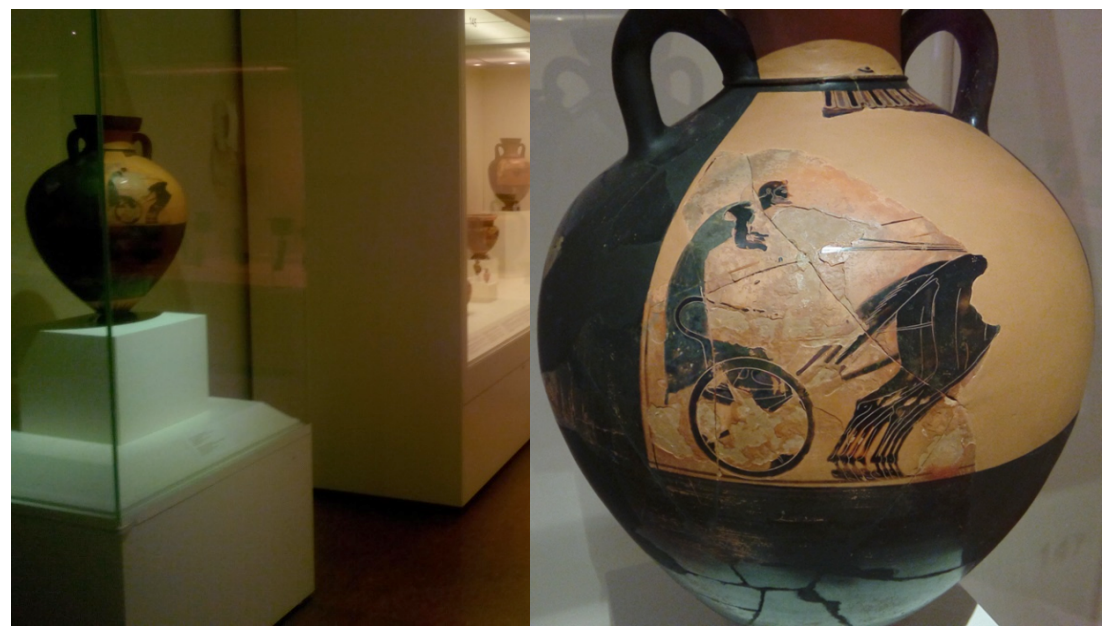

FIGURA 4 - Objeto 15. Ânfora panatenaica.

Fonte: Museu Arqueológico Nacional de Atenas, foto de Camilla Martins.

(C) Hellenic Ministry of Culture and Sports / Archaeological Receipts Fund. 
Para a distinção de ânforas panatenaicas das cerâmicas com forma e motivos panatenaicos (sejam elas figuras negras ou vasos em miniaturas), optou-se por manter a classificação do museu, encontrada nas etiquetas com informações das peças. Além disso, de forma geral, toda essa cultura material, exposta no NAM, foi produzida entre 575 e 359 a.C. e constitui-se, sem exceção, de figuras negras. Sendo a ânfora mais antiga de 575/25 a.C. e as quatro mais recentes de 360/59 a.C.

\section{Passado e presente}

As exposições, conforme Cazelli, Marandino e Studart (2003, p. 83), são meios peculiares de comunicação dos museus e, por isso, analisar a sua concepção é crucial. Para Hooper-Greenhill (1994, p. 21), o significado do objeto na exposição é condicionado pela relação que ele estabelece com os outros objetos e com os recursos utilizados, por meio de etiquetas, textos e outros, a fim de auxiliar na interpretação do visitante. De acordo com a autora (1994, p. 16), nesse sentido, há duas perspectivas de comunicação: a abordagem transmissora e a abordagem cultural. A primeira entende a comunicação como um processo de concessão e de envio de mensagens e transmissão de ideias, de uma fonte de informação para um receptor passivo. Já na segunda a realidade não se encontra intacta, é moldada por meio de um processo contínuo de negociação, que envolve os indivíduos a partir de suas experiências na construção ativa dos seus próprios significados.

Neste artigo, a concepção é o aspecto a ser analisado da comunicação. Pensa-se se a exposição do NAM possui como elemento central o objeto (modelo transmissor) ou o conceito (modelo cultural). Segundo Chelini e Lopes (2008, p. 213), se o objeto é central, temse um display de objetos dispostos segundo padrões como, por exemplo, a estética - considerase que o objeto fala por si só, sem necessidade de qualquer informação interpretativa. E, se a exposição possui como foco o conceito, terá uma compreensão baseada mais no texto e nos elementos gráficos do que nos objetos.

$\mathrm{Na}$ exposição do NAM, os vasos, por motivos de conservação, não podem ser tocados pelo visitante, estão em caixas de vidros, com uma iluminação intimista e focada nos objetos - isso significa que somente podem ser alcançados por meio da visão. Segundo Pomian (1984, p. 52-71), nos museus os artefatos se oferecem ao olhar não como peças decorativas mas sim como objetos detentores de prestígio e/ou que possuem valor histórico e/ou científico. São rodeados de cuidados, protegidos de furto e da deterioração, e possuem um alto valor de mercado mesmo sem ter um valor de uso, unindo o mundo visível (a realidade) ao invisível (o passado e, também, o sagrado) - são semióforos, ou seja, sem utilidade, são representantes do invisível e dotados de um significado que se desvela quando expostos ao olhar.

De acordo com Pomian (1984, p. 73), quanto mais significado se atribui a um objeto, menos interesse tem a sua utilidade. Contudo, de encontro a Pomian, como se pretende analisar a seguir, no NAM e na exposição, esses significados são construídos a partir do presente e os objetos são, de alguma forma, apropriados e úteis às intenções e ao discurso da instituição. 
Conforme Barros (2009), um museu "é produtor de discursos e, portanto, participa da construção do conhecimento histórico não apenas como fornecedor de materiais e fontes para o historiador, mas como agente que também produz as suas próprias leituras do conhecimento histórico". Dessa forma, o lugar onde se encontra o objeto é gerador de significados e o museu produz saberes e discursos, e a exposição é uma forma de expressá-los.

No caso da Grécia, por exemplo, Frontisi-Ducroux e Lissarrague (1990, p. 207) argumentam que as autoridades utilizam o seu patrimônio como uma estratégia diplomática, permitindo aos museus amigos receberem temporariamente as suas preciosas coleções. Nesse sentido, como escreve Hardwick (2003, p. 3), é interessante pensar em como diferentes aspectos do passado são selecionados e usados a fim de dar valor e status a culturas e sociedades subsequentes.

Os artefatos, sim, se oferecem ao olhar, são tomados de cuidados e unem de certa maneira o nosso momento ao passado, o invisível, segundo Pomian. Contudo, possuem significados, têm utilidade e não se desvelam simplesmente ao olhar, pois é preciso estudo, distanciamentos e aproximações entre a concepção que se tem de mundo e aquela do passado a fim de se construir algum conhecimento. Segundo Chelini e Lopes (2008, p. 219-20), a exposição faz "ver" os objetos, mas, para fazer "conhecer", deve responder a uma estratégia de comunicação que leve em conta as características do espaço-museu e das transformações que tais características imprimem ao conhecimento.

Nesse sentido, ir ao NAM e visitar a exposição de vasos é uma experiência principalmente visual na qual se evidencia o formato das peças e as suas cenas figurativas, que ficam em uma altura ideal para os olhos. Já as etiquetas - com suas informações de contexto - possuem letras pequenas e estão em inglês e em grego, mas não são atrativas ao olhar e ficam numa posição muito abaixo do campo da visão. Porém, os painéis explicativos (com informações de produção e de funções) geralmente são grandes e fáceis de ler, contendo parte do viés dado à exposição, sendo que a outra parte está na própria maneira de dispor as peças (em ordem cronológica, focando o formato e as pinturas) - reforçando, de certo modo, o modelo transmissor de exposição e o ponto de vista estético de interpretação do passado, permitindo a ideia de algo "clássico", que significa, neste caso, algo que é absolutamente sólido, forte, perfeito e eterno. Essa estratégia, segundo Chelini e Lopes (2008, p. 219), visa a tornar o objeto exposto um "objeto revelado" ao público.

Entretanto, os painéis explicativos, ao trazerem informações de produção e de funções rompem com isso, adquirem certo aspecto didático (modelo cultural) e mostram uma variedade de significações para os vasos no mundo antigo. Assim, evidenciar o conteúdo e as funções das peças retira a experiência baseada apenas na forma, no superficial. Apesar de que não se sabe quantas pessoas leem esses painéis ou mesmo as etiquetas.

De acordo com Papageorgiou-Venetas (1994, p. 338), relativamente poucos, principalmente aqueles com interesse acadêmico, visitam os museus e realizam boa parte da leitura ou usam guias de visitação bem pensados e elaborados. A maioria dos visitantes tem poucas horas para apreciar a exposição e, muitas vezes, estão em grupos recebendo apenas breves explicações de guias turísticos - uma forma de apropriação impessoal e, também, passiva. Portanto, em uma visita assim, o que permanece talvez seja aquilo que é 
mais facilmente apreendido, a exposição do ponto de vista visual - o modelo estético, que, conforme Tziovas (2008, p. 288), entende o passado como uma presença viva em forma de vestígios rastreados na cultura moderna, permitindo, estilística e esteticamente, certa continuidade entre passado e presente.

Outra observação interessante da exposição é sua última sala, com uma organização diferente do trajeto cronológico e um ambiente temático dedicado aos esportes, mas não em qualquer época e nem representado com qualquer técnica de pintura. Aborda o tema a partir da cerâmica de pinturas negras e vermelhas dos períodos Arcaico e Clássico, justamente o momento de grande produção de imagens na Antiguidade. Nesse ambiente, as ânforas e as cerâmicas do universo panatenaico aparecem em oito peças datadas entre 560 e 430 a.C.

Esse ambiente, a partir dessa temática, também coloca o objeto como central e, então, a experiência, de certa maneira, continua sendo, em sua maior parte, visual. As cenas mostram a atuação dos atletas; nas ânforas panatenaicas e cerâmicas do universo panatenaico, a face com a deusa Atena não é exibida, pois o importante parece ser mostrar a atividade física como elemento essencial da Antiguidade. E, também, do presente, como se fosse um aspecto atemporal da identidade grega, uma vez que, na atualidade, a Grécia é imaginada como a origem de algumas práticas esportivas e dos jogos olímpicos.

Sobre isso, de acordo com Rubio (2002, p. 134), desde o século XIX os sistemas ginásticos se inspiram na Grécia antiga e estão vinculados a elementos que os associam à educação. No século XIX, ainda, buscavam responder a uma demanda advinda da defesa dos Estados Nacionais e do aumento da produção capitalista.

Nesse contexto, aqueles atletas que escapam ao aspecto ideológico e mercantil do esporte "vivem o arquétipo do herói em toda a sua plenitude, seja pela demonstração de força e coragem, seja pela capacidade de realizar virtudes destinadas a poucos, seja até em determinados momentos pela morte trágica." (Rubio, 2002, p. 141). Arquétipo esse que, na sala temática da exposição, parece ser o mesmo que o do atleta antigo, um homem belo, vitorioso e herói.

Contudo, se essa sala for confrontada com o display onde as ânforas panatenaicas estão no centro do ambiente, então poderá se notar que os esportes referenciados na primeira eram praticados de forma distinta na Antiguidade, pois havia o contexto da festa religiosa e cívica. $\mathrm{O}$ aspecto religioso fica em evidência quando em uma mesma ânfora percebe-se de um lado uma competição e do outro a deusa Atena, e, também, quando a deusa Vitória está presente na cena com os atletas - detalhes que não aparecem na sala temática.

Assim, diferentemente da exposição cronológica, a sala temática evidencia o esporte como uma continuidade entre o atleta da Antiguidade e o contemporâneo ao materializar (tematicamente) um imaginário sobre o passado. Além disso, é possível refletir que o museu, a partir dela, imagina a sua própria comunidade nacional em uma perspectiva estética.

Por fim, esse modo de engajar e exibir a Antiguidade grega (tanto a partir da temática como da linearidade) nos ambientes dos museus é, de acordo com Romanisin $(2018$, p. 8), inseparável de debates políticos e sociopolíticos mais amplos sobre o significado da identidade nacional grega e seu lugar dentro da Europa. Como tal, fornece questionamentos relativos à relação entre herança cultural, materialidade e imaginação. 


\section{CONSIDERAÇÕES FINAIS}

Como se discutiu com Tziovas (2008), de forma geral, há quatro modelos para o entendimento do passado grego (o simbólico ou arqueológico, o orgânico ou romântico, o estético ou modernista e o crítico ou pós-modernista). Na análise da exposição do NAM notou-se como, principalmente, o esquema estético construiu certa imaginação a respeito da nação e sua ancestralidade a partir da centralidade da exibição nos objetos, da aplicação da visão, fundamentalmente, como meio comunicativo e da sensibilização do significado atlético e esportivo que as ânforas panatenaicas podem passar.

O imaginário antigo, como se pode notar nas imagens, memora um atleta herói (homem, belo e vitorioso) afortunado pela deusa Atena e, também, pela Vitória. Esse é o aspecto, no presente, que é apropriado pelo museu na apresentação da sala temática, mas sem a evidência de seu lado cívico e religioso. Isso, dentro de um modelo transmissor de exposição, passa a ideia de uma nação, a Grécia, construída pelos valores dos esportes e ocasiona a noção de uma continuidade em relação à Antiguidade, evocando certa ascendência e perpetuando identidades nas imagens da vida nacional.

Essa relação das antigas competições com a contemporaneidade não é simples como parece ser, quando apenas se olham as peças no museu e se pensa nos esportes. Há, junto dessa prática, toda uma construção de identidade envolvida em um discurso político de autodeterminação da nação e, ainda, um imaginário acerca do atleta, espécie de herói que a representa, o qual é reforçado pela cultura visual, estendendo-se para além das galerias do museu, uma vez que a iconografia dos jogos também se encontra em cartões postais, em pequenos vasos vendidos como souvenirs, em estampas de camisetas, entre outros.

Assim, questões do presente como a forma de elaborar a exposição, o seu foco no objeto, e a maneira de abordar o antigo, pelo viés visual, em um modelo estético, atravessam a construção de um conhecimento sobre o passado. Os artefatos são específicos de um período e de um lugar na Antiguidade, como o trajeto linear procura mostrar, apesar de adotar uma história coesa e sem interrupções da cerâmica de forma geral; porém, na sala temática eles são ressignificados e materializam valores de uma identidade nacional, ou seja, o mito do atleta.

\section{Agradecimentos}

Agradeço ao financiamento da CAPES, ao Programa de Pós-Graduação em História da UFPR, ao Museu Arqueológico Nacional de Atenas e aos professores doutores Renata Garraffoni, José Geraldo Grillo, Roseli Boschilia, Pedro Ipiranga, Fábio Cerqueira e Maria Cecília Coelho. Além disso, agradeço às bibliotecas que me receberam e permitiram o desenvolvimento da minha pesquisa, bibliotecas da UFPR, biblioteca do MAE/USP e biblioteca da Escola Americana de Estudos Clássicos em Atenas (Blegen Library). 


\section{REFERÊNCIAS}

BARROS, José. História da cultura material. Notas sobre um campo histórico em suas relações intradisciplinares e interdisciplinares. Patrimoniuss, Maricá, [n. p.], mar. 2009.

CAZELLI, Sibele; MARANDINO, Martha; STUDART, Denise. Educação e comunicação em museus de ciências. Aspectos históricos, pesquisa e prática. In: GOUVÊA, Guaracira; MARANDINO, Martha (org.). Educação e museu. A construção social do caráter educativo dos museus de ciências. Rio de Janeiro: Editora Access, 2003, p. 83-106.

CHELINI, Maria Júlia; LOPES, Sônia. Exposições em museus de ciências. Reflexões e critérios para análise. Anais do Museu Paulista, São Paulo, v. 16, n. 2, p. 205-238, jul./dez. 2008.

DÍAZ-ANDREU, Margarita. A world History of nineteenth-century Archaeology Nationalism, Colonialism, and the past. Oxford: Oxford University Press, 2007.

FERREIRA, Lúcio. Patrimônio, pós-colonialismo e repatriação arqueológica. Ponta de Lança, São Cristóvão, v. 1, n. 2, p. 37-62, abr./out. 2008.

FRANCISCO, Gilberto. Panatenaicas. Tradição, permanência e derivação. 394f. Tese (Doutorado em Arqueologia) - Museu de Arqueologia e Etnologia, Universidade de São Paulo, São Paulo, 2012.

FRANCISCO, Gilberto. Vasos áticos e tradição panatenaica: uma reflexão a partir do acervo do Museu Real Ontário, Toronto. Interfaces Brasil/Canadá, Canoas, v. 15, n. 1, p. 252-279, 2015.

FRANCISCO, Gilberto. Figuras de atletas e a noção de representação nas ânforas panatenaicas. Hélade, Niterói, v. 2, n. 1, p. 10-23, 2016.

FRONTISI-DUCROUX, Françoise; LISSARRAGUE, François. Vingt ans de vases grecs: tendances actuelles des études en iconographies grecques (1970-1990). Mètis. Anthropologie des Mondes Grecs Anciens, v. 5, n. 1-2, p. 205-224, 1990.

GAZI, Andromache. National museums in Greece: History, Ideology, Narratives. In: ARONSSON, Peter; ELGENIUS; Gabriella (ed.). Building national museums in Europe 17502010. EuNaMus Report n. 1. Linköping: Linköping University, 2011. p. 363-399.

GRILLO, José Geraldo. A nudez heroica na pintura da cerâmica ática. In: FUNARI, Pedro Paulo; MARQUETTI, Flávia Regina (org). Corpo a corpo. Representações antigas e modernas da figura bumana. São Paulo: Editora Fap-Unifesp, 2014, p. 23-31.

GRILLO, José Geraldo. A imaginação do passado e a construção da identidade grega. O caso da arqueologia clássica no século XIX. In: SILVA, Glaydson; GARRAFFONI, Renata; FUNARI, Pedro Paulo; GRALHA, Júlio; RUFINO, Rafael (org.). Antiguidade como presença. Antigos, modernos e os usos do passado. Curitiba: Prismas, 2017a, p. 185-193.

GRILLO, José Geraldo. Warburg, Pathosformel e a gestualidade na arte grega. Algumas reflexões. Figura. Studies on the Classical Tradition, Campinas, v. 5, n. 1, p. 103-133, 2017b. 
HAMILAKIS, Yannis. The nation and its ruins. Antiquity, Archaeology and National Imagination in Greece. Oxford: Oxford University Press, 2007.

HARDWICK, Lorna. Reception studies. Oxford: Oxford University, 2003.

HOOPER-GREENHILL, Eilean. The educational role of the museum. London: Routledge, 1994.

KALTSAS, Nikolaos et al. National Archaeological Museum. Athens: Kapon, 2010.

KYLE, Donald. Gifts and glory. Panathenaic and other greek athletic prizes. In: NEILS, Jenifer (ed.). Worshipping Athena. Panathenaia and Parthenon. London: University of Wisconsin, 1996. p. 106-136.

KOURI, Maria. Ownership and participation. Democratizing the governance of antiquities. Zarzqdzanie W Kulturze, v. 18, n. 1, p. 41-60, 2017.

LAGOGIANNI-GEORGAKARAKOS, Maria. National Archaeological Museum 1866-2016. Activities and synergies in Athens for a great anniversary. Athens: National Archaeological Museum, 2016.

LUND, John; RASMUSSEN, Bodil. Guides to the National Museum. Near Eastern and Classical Antiquities. Greeks, Etruscans, Romans. Athens: The National Museum, 1995.

MARK, Ira. The sanctuary of Athena Nike in Athens. Architectural stages and chronology. Princeton: American School of Classical Studies at Athens, 1993.

MARTINS, Camilla. O imaginário antigo e as ânforas panatenaicas do Museu Arqueológico Nacional de Atenas. 148 f. Tese (Doutorado em História) - Setor de Ciências Humanas, Universidade Federal do Paraná, Curitiba, 2020.

MARTINS, Camilla. A iconografia dos vasos panatenaicos de Atenas entre 566 a.C. e 320 a.C. 136 f. Dissertação (Mestrado em História) - Setor de Ciências Humanas, Letras e Artes, Universidade Federal do Paraná, Curitiba, 2014.

MESKELL, Lynn (ed.). Archaeology under fire. Nationalism, politics and heritage in the Eastern Mediterranean and Middle East. London; New York: Routledge, 2002.

NATIONAL ARCHAEOLOGICAL MUSEUM. Website. Athens, 2008-2016c. Disponível em: http://www.namuseum.gr. Acesso em: 5 set. 2017.

PAPAGEORGIOU-VENETAS, Alexandros. Athens. The ancient heritage and the historic cityscape in a modern metropolis. Athens: The Archaeological Society at Athens Library, 1994.

PAPASPYRIDI-KAROUZOU, Semni. A proto-panathenaic amphora in the National Museum at Athens. American journal of Archaeology, v. 42, n. 4, p. 495-505, Oct./Dec. 1938.

PHILIPPAKI, Barbara. Vases of the National Archaeological Museum of Athens. Athens: Apollo, 1970.

POMIAN, Krzysztof. Colecção. In: ROMANO, Ruggiero (ed.). Enciclopédia Einaudi, v. 1, Memória - História. Lisboa: Imprensa Nacional, Casa da Moeda, 1984. p. 51-86. 
ROMANISIN, Alecsandra. Imagining Greece. Sensing antiquity in two Athenian museums. 2018. 69f. Dissertação (Master of Arts in Public Issues Anthropology) - University of Waterloo, Waterloo, Ontario, 2018.

RUBIO, Katia. Do olimpo ao pós-olimpismo. Elementos para uma reflexão sobre o esporte atual. Revista Paulista de Educação Física, São Paulo, v. 16, n. 2, p. 130-43, jul./dez. 2002.

SILVA, Glaydson. A antiguidade romana e a desconstrução das identidades nacionais. In: FUNARI, Pedro Paulo; ORSER, Charles; SCHIAVETTO, Solange (org.). Identidades, discurso epoder. Estudos de arqueologia contemporânea. São Paulo: Annablume, 2005. p. 91-101.

TZIOVAS, Dimitris. Reconfiguring the past. Antiquity and Greekness. In: DAMASKOS, Dimitris; PLANTZOS, Dimitris (ed.). A singular antiquity. Archaeology and Hellenic Identity in twentieth-century Greece. Athens: Mouseio Benaki, 2008. p. 287-298.

VERNANT, Jean-Pierre. Entre mito e politica. São Paulo: EDUSP, 2001.

WARNER, Marina. Monuments and maidens. The Allegory of the Female Form. Berkeley; Los Angeles: University of California Press, 2000. 